\section{Obs Gyne Review - Journal of Obstetric and Gynecology}

\title{
The ambit of congenital malformations in the Kachchh district- a hospital-based study
}

\author{
Mehta D. ${ }^{1}$, Pawani C. ${ }^{2 *}$, B Kukadiya S. ${ }^{3}$, Pandya N. ${ }^{4}$ \\ DOI: https://doi.org/10.17511/joog.2020.i06.02 \\ 1 Dhwani Mehta, Third Year Resident, Department of Obstetrics and Gynecology, Gujarat Adani Institute of Medical Science, Kutch, Gujarat, \\ India. \\ 2* Charmi Pawani, Assistant Professor, Department of Obstetrics and Gynecology, Gujarat Adani Institute of Medical Science, Kutch, \\ Gujarat, India. \\ ${ }^{3}$ Snehal B Kukadiya, Second Year Resident, Department of Obstetrics and Gynecology, Gujarat Adani Institute of Medical Science, Kutch, \\ Gujarat, India. \\ 4 Nimish Pandya, Profesoor and Head, Department of Obstetrics and Gynecology, Gujarat Adani Institute of Medical Science, Kutch, \\ Gujarat, India.
}

Background and Aim: Quantifying birth defects in a population is felt as a need as it helps inappropriate allocation of the health budget to tackle and reduce perinatal, neonatal, and infant mortality rates. Hence a study on congenital anomalies was undertaken in the region of Kachchh district. Material and Methods: Present cross-sectional study was performed on 10 patients diagnosed with having congenital malformed fetuses at tertiary care center- G.K. General Hospital, Bhuj, Kachchh district, Gujarat, India over three months - January, February, March 2019. Results: Mean age of the study participants were 22.3 years, most $(70 \%)$ of the study participants were primigravida. Hydrocephalus was the most common birth defect among study participants. Eighty percentages $(80 \%)$ of study participants had gross anomalies. Sixty percentages $(60 \%)$ of participants had the outcome of termination. Conclusion: Congenital anomalies were in babies to mothers between 20-30 years of age. Once an anomaly is detected, various management options are to be discussed with the patients in consultation with a neonatologist, pediatric surgeon, and neurosurgeon when necessary.

Keywords: Birth defect, Congenital anomalies, Hydrocephalus, Pregnancy

Corresponding Author

Charmi Pawani, Assistant Professor, Department of Obstetrics and Gynecology, Gujarat Adani Institute of Medical Science, Kutch, Gujarat, India.

Email: dhwanipmehta02@gmail.com
How to Cite this Article To Browse

Mehta D, Pawani C, Kukadiya SB, Pandya N. The ambit of congenital malformations in the Kachchh district- a hospital-based study. Obs Gyne Review J Obstet Gynecol. 2020;6(6):114-119.

Available From

https://obstetrics.medresearch.in/index.php/joog/art icle/view/122

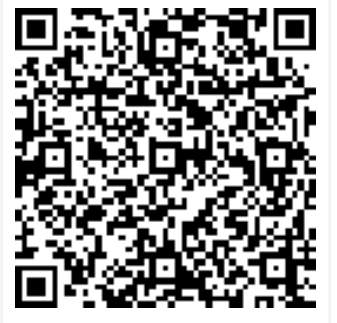

Manuscript Received 2020-11-07

Conflict of Interest No

(C) 2020 by Dhwani Mehta, Charr Social Welfare Society. This is ar
Review Round 1 2020-11-17

Funding Nil

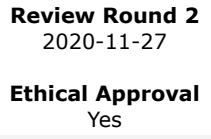

Review Round 3

Accepted 2020-12-07

Plagiarism $\mathbf{X}$-checker $7 \%$

Note 


\section{Introduction}

Congenital anomalies are defined as structural and functional abnormalities including metabolic disorders present at birth. Several known factors are associated such as maternal infection like TORCH, genetic factors, drugs, maternal age, and consanguinity. Screening in the late first ( $11-13$ weeks ) and second trimester (20- 24 weeks) is an important tool to reduce the prevalence. Congenital anomalies represent defects in morphogenesis during early fetal life.

Congenital anomalies occur all over the world with similar frequency. According to the WHO document of 1972 , the term congenital malformations should be confined to structural defects at birth [1]. Congenital anomalies account for about $8-15 \%$ of perinatal deaths and $13-16 \%$ of neonatal deaths in India $[2,3]$.

Centre for Disease Control and Prevention (CDC) the USA, had reported an incidence of about $3 \%$ of all live births in the USA during 2004-2006 [4]. It is the most important cause of under-five mortality in developing nations like India and accounts for about 61 to $69.9 / 1000$ of all live births5 This high prevalence warrants the need to take immediate steps to tackle the problem on a war footing, more so when $70 \%$ of these defects are preventable [5].

India ranks second in the world concerning the reported occurrence of congenital anomalies in neonates and children. This fact highlights the urgency and importance of documenting all congenital malformations occurring in neonates born in a hospital setting, to focus and develop appropriate preventive and remedial strategies. Quantifying birth defects in a population is a felt need as it helps inappropriate allocation of the health budget to tackle and reduce perinatal, neonatal, and infant mortality rates. Hence a study on congenital anomalies was undertaken. Evaluation is a continuous process that's why a deep insight into the evolution of congenital anomalies and dysmorphology is needed.

\section{Material and Methods}

A present cross-sectional study was performed on 10 patients diagnosed with having congenital malformed fetuses at tertiary care center- G.K. General Hospital, Bhuj, Kachchh district, Gujarat, India over three months - January, February, March 2019.
Approval was taken from the Institutional Human Ethics Committee before the commencement of the study. Written expressed consent was taken from the parents. The babies were thoroughly evaluated to identify the nature, severity of structural congenital malformations and to classify them as single or multiple malformation syndrome or associations. Appropriate investigations and treatment were provided to neonates who required them.

\section{Inclusion Criteria}

01. Patients diagnosed with congenital malformed fetus irrespective of gestational age and time of presentation (i.e. antenatal, during labor, or post part Partum period)

02. All babies with congenital malformations diagnosed before, at, and after birth i.e. Inutero, Intra Partum and Post-Partum.

\section{Exclusion criteria}

01. All intrinsic anomalies e.g of the cardio-vascular system are excluded which are not grossly apparent.

\section{Invasive Procedure}

01. MTP (Medical Termination of pregnancy)

02. Induction of labor

03. Normal Vaginal delivery with or without episiotomy

04. Cesarean section

\section{Statistical analysis}

The data was coded and entered into a Microsoft Excel spreadsheet. The analysis was done using SPSS version 15 (SPSS Inc. Chicago, IL, USA) Windows software program. The variables were assessed for normality using the KolmogorovSmirnov test. Descriptive statistics were calculated.

\section{Results}

\section{CNS MALFORMATIONS}

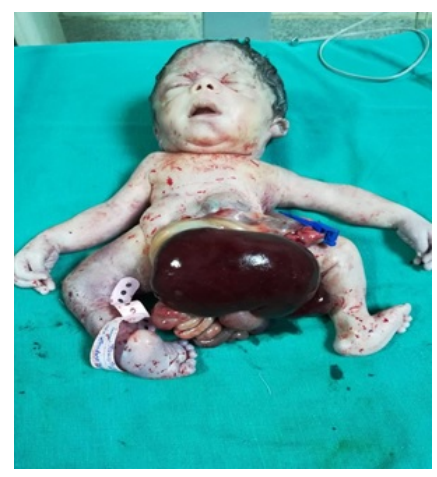




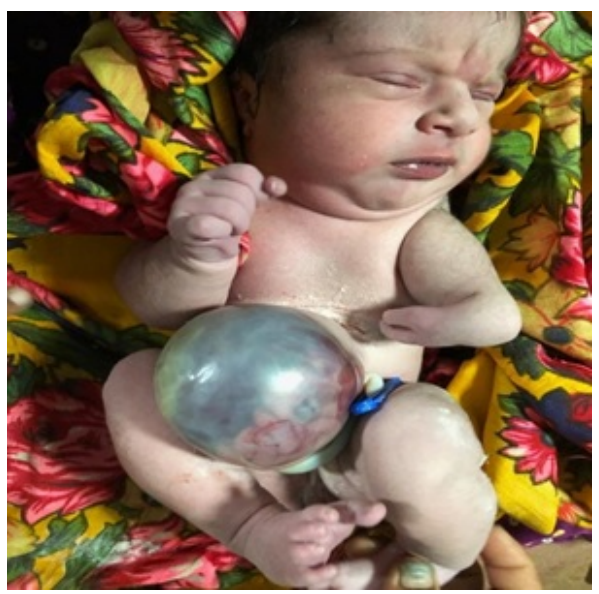

Fig-1: Omphalocoele, imperforate anus, cleft lip, cleft palate detected at 37 weeks of gestation.

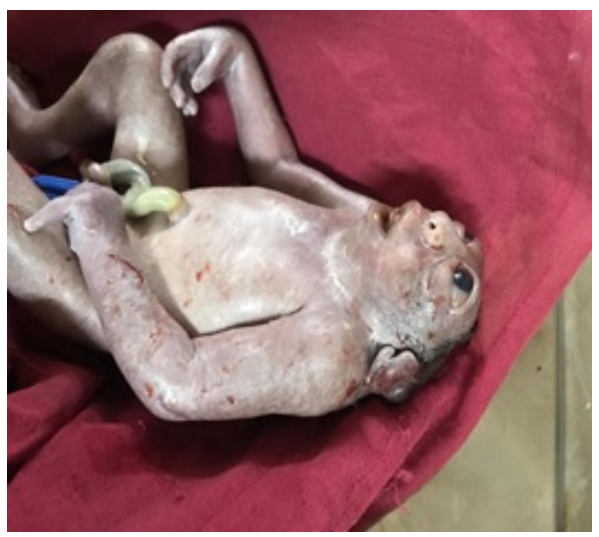

Fig-2: Anencephaly at 19.3 weeks of gestation.

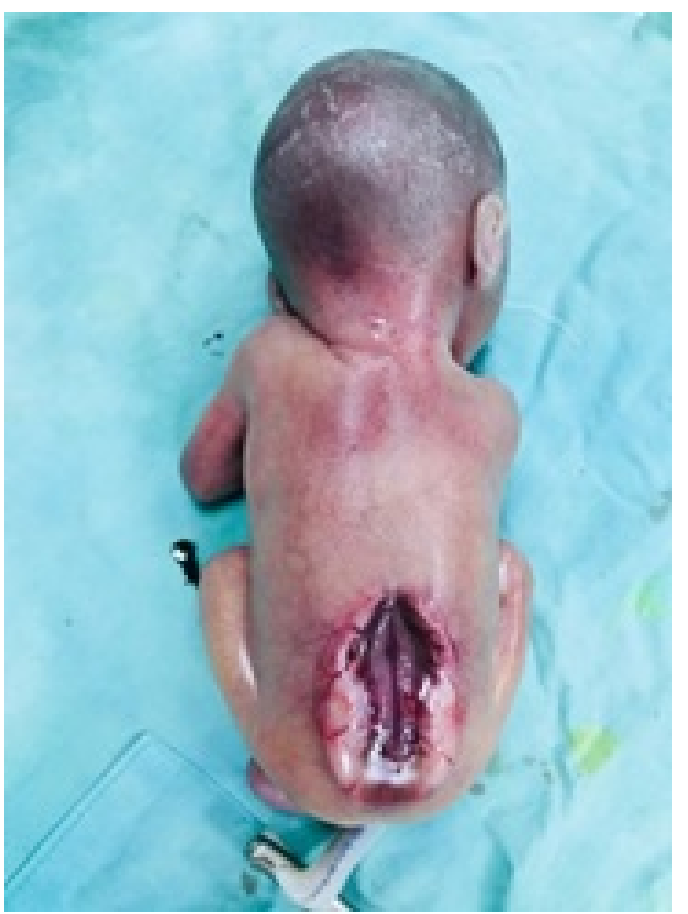

Fig-3: Spina bifida with Arnold Chiari malformation type 2 .

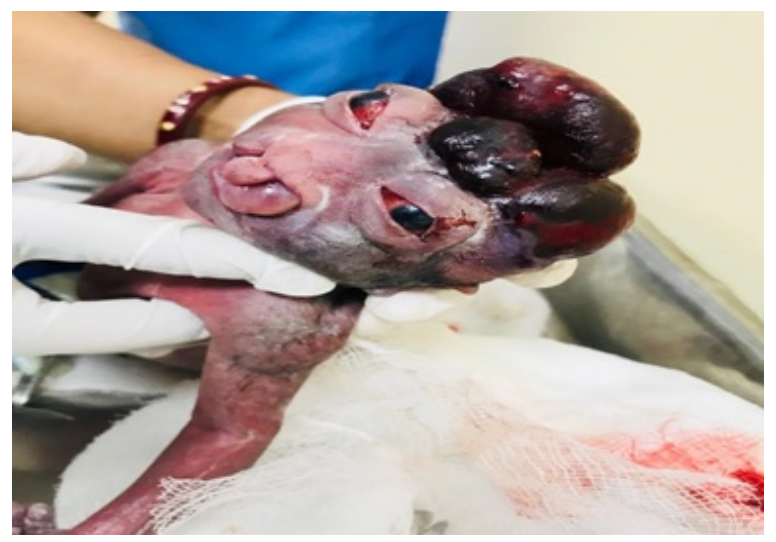

Fig-3: Exencephaly with cleft lip and cleft palate at 30.3 weeks gestation.

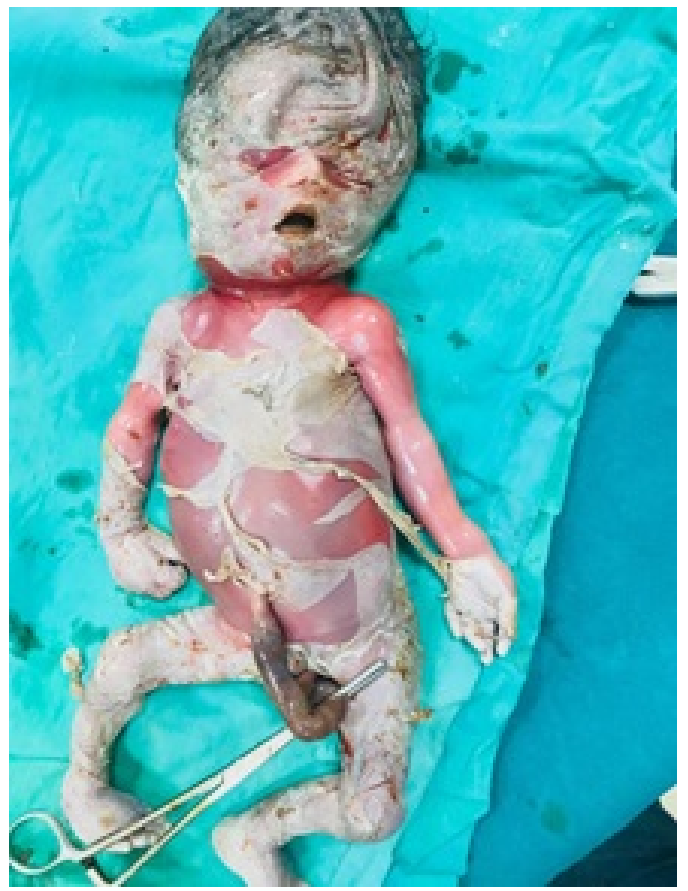

Fig-4: Hydrocephalus with intra uterine fetal death presenting in obstructed labour at 36 weeks of gestation.

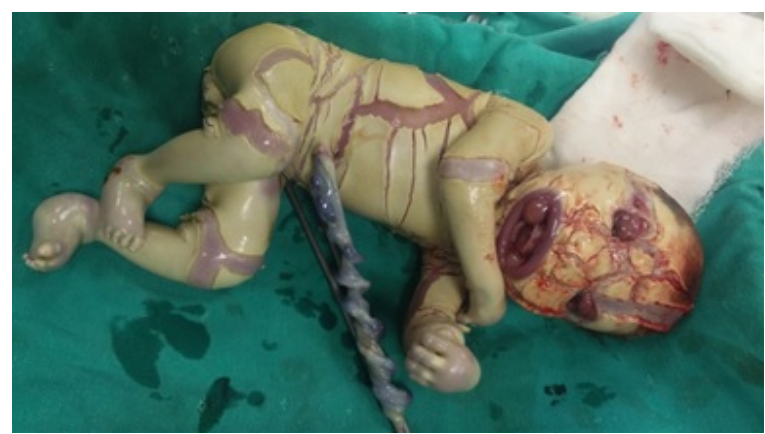

Fig-5: Cleft lip, cleft palate with congenital icthyosis at 37 weeks of gestation. 
Table-1: Age-wise distribution of study participants.

\begin{tabular}{|l|l|l|l|l|}
\hline & Maximum Age & Minimum Age & Mean Age & Standard Deviation \\
\hline Age & 26 & 20 & 22.3 & 2.05 \\
\hline
\end{tabular}

Table 1 describes the Age-wise distribution of study participants.

- The mean age calculated is 22.3 years of presentation with the maximum age being 26 years and the minimum age being 20 years.

Table-2: Distribution of study participants according to the Gravida status.

\begin{tabular}{|l|l|l|}
\hline \multicolumn{1}{|c|}{ Gravida } & Number & \multicolumn{1}{c|}{ Percentage (\%) } \\
\hline Primi & 7 & 70 \\
\hline Second & 2 & 20 \\
\hline Third & 1 & 10 \\
\hline Total & 10 & 100 \\
\hline
\end{tabular}

Table 2 illustrates the distribution of study participants according to the Gravida status.

- Most of the patients - $70 \%$ are primigravida patients, $20 \%$ second gravid, and $10 \%$ third gravida.

Table-3: Distribution of study participants according to the Parity.

\begin{tabular}{|l|l|l|}
\hline \multicolumn{1}{|c|}{ Parity } & \multicolumn{1}{c|}{ Number } & \multicolumn{1}{c|}{ Percentage (\%) } \\
\hline One & 8 & 80 \\
\hline Two & 2 & 20 \\
\hline Total & 10 & 100 \\
\hline
\end{tabular}

Table 3 shows the distribution of study participants according to the Parity.

- Most of the patients - $80 \%$ were primipara, while $20 \%$ had been the second para.

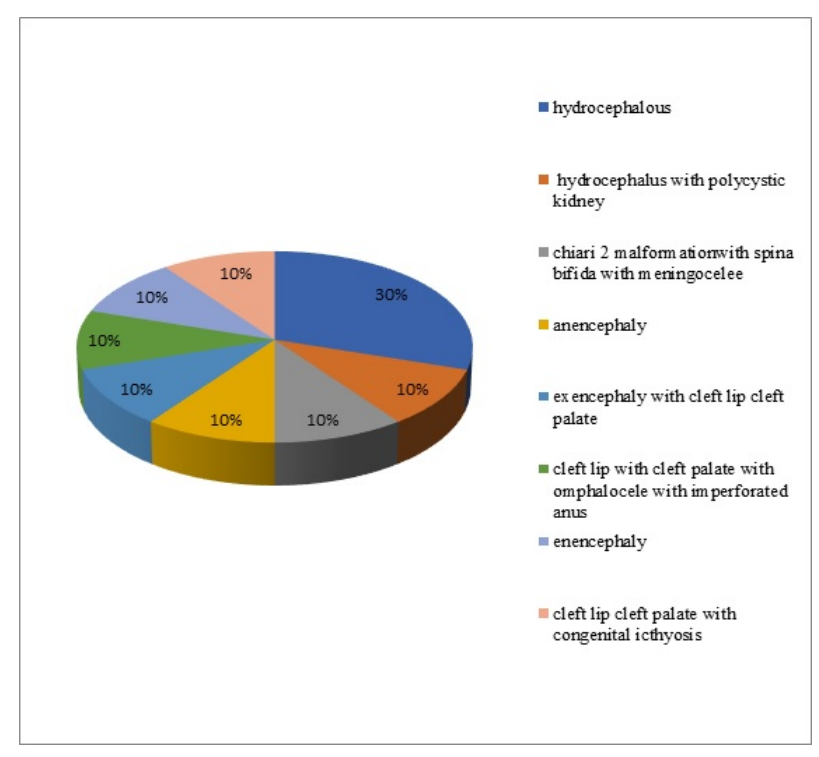

Fig-6: Distribution of Congenital anomalies of the study participants.
Figure 6 explains the distribution of Congenital anomalies of the study participants.

- $30 \%$ of participants had Hydrocephalous, $10 \%$ had Anencephaly, while $10 \%$ of Hydrocephalus with polycystic kidney, $10 \%$ Arnold Chiari 2 malformation with spina bifida with meningocele, 10\% Enencephaly, 10\% cleft lip with cleft palate with omphalocele with the imperforated anus, $10 \%$ cleft lip cleft palate with congenital ichthyosis, $10 \%$ exencephaly with cleft lip cleft palate respectively.

Table-4: Distribution of study participants according to time of detection.

\begin{tabular}{|l|l|l|l|l|}
\hline & $\begin{array}{c}\text { Maximum time } \\
\text { (weeks) }\end{array}$ & $\begin{array}{c}\text { Minimum time } \\
\text { (weeks) }\end{array}$ & $\begin{array}{c}\text { Meantime } \\
\text { (week) }\end{array}$ & $\begin{array}{c}\text { Standard } \\
\text { Deviation }\end{array}$ \\
\hline $\begin{array}{l}\text { Time of } \\
\text { detection }\end{array}$ & 19.3 & 37 & 29.6 & 5.5 \\
\hline
\end{tabular}

- The mean time of detection calculated is 22.3 years of presentation with maximum time being 37 weeks years and minimum time being 19.3weeks.

Table-5: Distribution of study participants according to the presence of gross anomalies.

\begin{tabular}{|l|l|l|}
\hline \multicolumn{1}{|c|}{ Gross anomalies } & Number & \multicolumn{1}{c|}{ Percentage (\%) } \\
\hline Yes & 8 & 80 \\
\hline No & 2 & 20 \\
\hline Total & 10 & 100 \\
\hline
\end{tabular}

Table 5 describes the distribution of study participants according to the presence of gross anomalies.

- Most of the participants $80 \%$ had gross anomalies while $20 \%$ did not have gross anomalies.

Table-6: Distribution of study participants according to consanguineous marriage.

\begin{tabular}{|l|l|l|}
\hline \multicolumn{1}{|c|}{ Consanguineous marriage } & Number & Percentage (\%) \\
\hline Yes & 6 & 60 \\
\hline No & 4 & 40 \\
\hline Total & 10 & 100 \\
\hline
\end{tabular}

Table 6 explains the distribution of study participants according to consanguineous marriage.

- Most of the participants (60\%) had Consanguineous marriage while $40 \%$ did not have a consanguineous marriage.

Table-7: Distribution of study participants according to anomaly scan.

\begin{tabular}{|l|l|l|}
\hline \multicolumn{1}{|c|}{ Anomaly scan } & \multicolumn{1}{|c|}{ Number } & Percentage (\%) \\
\hline Yes & 9 & 90 \\
\hline No & 1 & 10 \\
\hline
\end{tabular}


Total 100

Table 7 shows the distribution of study participants according to the anomaly scan.

Most of the participants $90 \%$ had an anomaly scan while $10 \%$ did not have an anomaly scan.

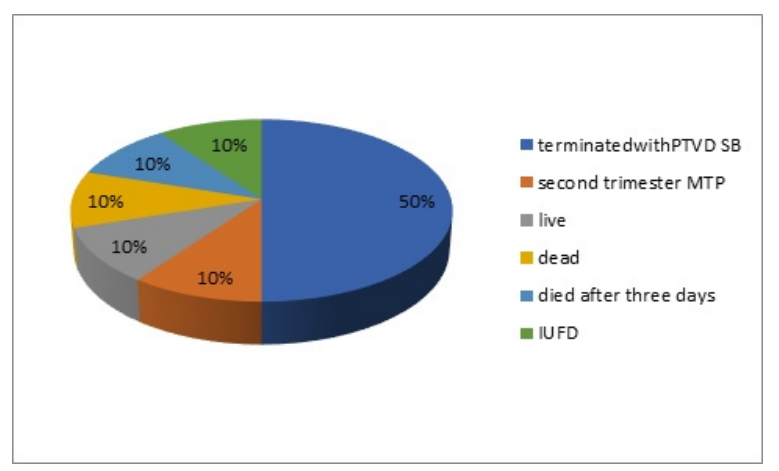

\section{Fig-7: distribution of study participants} according to the outcome.

Figure 8 describes the distribution of study participants according to the outcome.

- Fifty percentages of participants had terminated pregnancy with PTVD SB, while $10 \%$ had second trimester MTP, $10 \%$ of neonates lived, $10 \%$ died, $10 \%$ died after three days of NICU care and $10 \%$ had IUFD.

Table-8: Distribution of study participants according to the termination of pregnancy.

\begin{tabular}{|l|l|l|}
\hline \multicolumn{1}{|c|}{ Termination } & Number & \multicolumn{1}{c|}{ Percentage (\%) } \\
\hline TIP & 7 & 70 \\
\hline spontaneous labor & 2 & 20 \\
\hline obstructed labor & 1 & 10 \\
\hline Total & 10 & 100 \\
\hline
\end{tabular}

Table 8 shows the distribution of study participants according to the Termination of Pregnancy.

- Most of the participants $70 \%$ had TIP while $20 \%$ had spontaneous labor and $10 \%$ had obstructed labor.

\section{Discussion}

Teratology and Dysmorphology are terminologies used to describe the various embryological, structural, functional, or bio-metabolic disorders in a developing fetus giving rise to congenital malformations [6]. Today, "birth defects" have emerged as a major health concern globally, more so in developed countries where they contribute significantly to neonatal and early childhood mortality.
These malformations account for 3\% of "major" structural defects, and 15\% of "minor" anomalies [6].

The present cross-sectional study was performed on 10 patients diagnosed with having congenital malformed fetuses at tertiary care center- G.K. General Hospital, Bhuj, Gujarat, India over three months - January, February, and March 2019.

The mean age calculated is 22.3 years of presentation with the maximum age being 26 years and the minimum age being 20 years. Similar results are obtained by $\mathrm{Dr}$. Taksande $\mathrm{A}$ et al and Arjun Singh, et al $[2,7]$. Though most of the studies stated that parity of the mother does not seem to influence the incidence of congenital anomalies a higher percentage of congenital anomalies were seen in the birth order of 1 in the present study this is similar to other studies like Swain et al, $\mathrm{R}$. Kulsherestha et al, Chathurvedi et al, and Grover N. et al [8-11].

Thirty percent of participants were hydrocephalous, $10 \%$ were of enencephaly, while $10 \%$ of Hydrocephalus with polycystic kidney, $10 \%$ Arnold Chiari 2 malformation with spina bifida with meningocele, 10\% Enencephaly, 10\% cleft lip with cleft palate with omphalocele with the imperforated anus, $10 \%$ cleft lip cleft palate with congenital ichthyosis, $10 \%$ exencephaly with cleft lip cleft palate respectively.

This type of frequency was also reported by Swain et al, Gupth $\mathrm{S}$ et al, Kalaiselvan $\mathrm{G}$ et al and Pandya $M$ et al $[8,12,13,14]$. Fifty percentages of participants had terminated pregnancy with PTVD SB, while $10 \%$ had second trimester MTP, $10 \%$ of neonates lived, $10 \%$ died, $10 \%$ died after three days and $10 \%$ had IUFD.

Social awareness about consanguinity and if unavoidable, genetic counseling is important to measure what can be done to reduce the consanguinity.

\section{Conclusion}

Congenital anomalies were in babies to mothers between 20-30 years of age. Once an anomaly is detected, various management options are to be discussed with the patients in consultation with a neonatologist, pediatric surgeon, and neurosurgeon when necessary. If parents are willing to continue the pregnancy with compatible congenital anomalies in the baby then pregnancy may be continued. 
But if the congenital anomaly is incompatible with life then pregnancy should be terminated.

\section{What does the study add to the existing knowledge?}

The study of malformations should include live and stillborn babies to get a realistic picture of the incidence of malformations. The autopsy should be included in the routine investigation of birth defects as a large proportion of defects is found at autopsy. A careful screening and premarital counseling / Preconceptional counseling for possible congenital malformation may be undertaken. Preventive genetics can be practiced e.g. Pre-implantation diagnosis by recognition of individuals who are at an increased risk for producing offspring with a hereditary disorder or in carriers. Hence mothers with a positive family history of malformations and bad obstetric history should be screened antenatally as well as pre conceptionally for the early detection of possible malformations thereby, reducing the mortality rates.

\section{Author's contribution}

\section{Dr. Dhwani Mehta: Concept}

Dr. Charmi Pawani: Study design and manuscript preparation

Dr. Snehal B Kukadiya: Statistical analysis

Dr. Nimish Pandya: Manuscript preparation

\section{Reference}

01. Patel ZM, Adhia RA. Birth defects surveillance. Indian J Pediatrics. 2005;72(6)489-491.

doi: $10.1007 /$ BF02724426 [Crossref]

02. Taksande A, Vilhekar $K$, Chaturvedi $P$, Jain $M$. Congenital malformations at birth in Central India- A rural medical college hospital-based data. Indian J Human Genet. 2010;16(3)159163.

doi: $10.4103 / 0971-6866.73412$ [Crossref]

03. Bhat BV, Ravikumar M. Perinatal mortality in india-need for introspection. Indian $\mathrm{J}$ Maternal Childhealth. 1996;7;31-33.

[Crossref]
04. CDC. Key findings- Updated National birth prevalence estimates for selected birth defects in the United States, 2004-2006.

Available at: [Article] [Crossref]

05. Sharma R. Birth defects in India: Hidden truth, need for urgent attention. Indian J Hum Genet. $2013 ; 19(2) 125-129$.

doi: 10.4103/0971-6866.116101 [Crossref]

06. Sadler T, Langman J. Birth defects and prenatal diagnosis, In- Leland J, editor, Langman's Medical Embryology. 12th ed, PhiladelphiaWolters Kluwer Health/Lippincott Williams and Wilkins. 2012;117-129.

[Crossref]

07. Singh A, Gupta RK. Pattern of Congenital Anomalies in Newborn- A Hospital Based Prospective Study. JK Science. 2009;11(1)11-5. [Crossref]

08. Swain S, Agarwal S, Bhatia bd. Congenital malformations at birth. Indian Pediatric. 1994;31(10)1187-1191.

[Crossref]

09. Kulshrestha R, Nath M, Upadhyaya P. Congenital malformations in live born infants in a rural community. Indian Pediatr. 1983;20(1)45-49. [Crossref]

10. Chaturvedi $P$, Banerjee KS. Spectrum of congenital malformations in the newborns from rural Maharashtra. Indian J Pediat. 1989;56(4)501-507.

doi: $10.1007 /$ BF02722424 [Crossref]

11. Grover N. Congenital malformations in Shimla. The Indian J Pediat. 2000;67(4)249-251. doi: $10.1007 /$ BF02758158 [Crossref]

12. Pandya M, Thakkar J. Study of gross congenital malformations in newborn. J Evol Med Dent Sci. 2013;2;4988-4993.

[Crossref]

13. Kulkarni MI. Prenatal diagnosis of genetic disorders. Indian Pediat. 1995;32(11)1229-38. [Crossref]

14. Kalaiselvan G. a study on incidence of congenital anomalies in rural population of cuddaloree district in Tamil Nadu. Rural Med. 2012;40-43.

[Crossref] 